\title{
IDEB, AVALIAÇÕES EXTERNAS E GESTÃO EDUCACIONAL: PERCEPÇÕES DE GESTORES ESCOLARES SOBRE USOS E IMPLICAÇÕES ${ }^{1}$
}

\author{
IDEB, EXTERNAL EVALUATIONS AND EDUCATIONAL MANAGEMENT: \\ PERCEPTIONS OF SCHOOLS MANAGERS ON USES AND IMPLICATIONS
}

\author{
Daniel Abud Seabra Matos ${ }^{2}$ \\ Breynner Ricardo de Oliveira ${ }^{3}$ \\ Zara Figueiredo Tripodi ${ }^{4}$
}

\begin{abstract}
Resumo
Buscamos, a partir da percepção de gestores, conhecer as lógicas de gestão escolar em municípios mineiros, por meio da sua interface com iniciativas de medida e avaliação federais. No total, participaram cinco escolas públicas de quatro municípios do estado de Minas Gerais. Realizamos entrevistas semiestruturadas individualmente com cinco gestoras. Utilizamos uma abordagem qualitativa, sendo as entrevistas analisadas por meio de análise de conteúdo. Nesse sentido, empregamos as seguintes categorias analíticas: a) modificação da gestão escolar; b) IDEB e qualidade em educação; c) modificação do trabalho pedagógico do professor. Em síntese, nossos resultados apontam para um forte efeito de indução que as avaliações externas e o IDEB têm produzido nas escolas e nos profissionais da educação, o que envolve questões como o estabelecimento de metas, monitoramento intenso das escolas e replanejamento institucional. Portanto, identificamos diversos usos e implicações do IDEB e avaliações externas. Tomados em conjunto, nossos resultados corroboram a literatura educacional.
\end{abstract}

Palavras chave: IDEB; avaliações externas; gestão educacional.

\begin{abstract}
Considering the perception of school managers, this paper analyses the interface among external evaluations, Index of Development of Basic Education (IDEB) and the strategies adopted by schools in the municipalities of Minas Gerais, Brazil. Five public schools from four municipalities in the state were selected. Oriented by a qualitative approach, we conducted individual semi-structured interviews with five school managers. The interviews were analyzed through content analysis, based on the following analytical categories: a) modification of school management; b) IDEB and quality in education; c) modification of the

\footnotetext{
${ }^{1}$ Artigo referente à mesa redonda do SiPEd.

${ }^{2}$ Universidade Federal de Ouro Preto, Mariana, Brasil. E-mail: dseabram@gmail.com

Professor adjunto do Departamento de Educação e do Programa de Pós Graduação em Educação.

${ }^{3}$ Universidade Federal de Ouro Preto, Ouro Preto, Brasil. E-mail: breynner.oliveira@ gmail.com

Professor adjunto do Centro de Educação Aberta e a Distância e do Programa de Pós Graduação em Educação.

${ }^{4}$ Universidade Federal de Ouro Preto, Mariana, Brasil. E-mail: zarafigueiredo@gmail.com Professora adjunta do

Departamento de Educação e do Programa de Pós Graduação em Educação.
}

Revista Devir Educação, Lavras, vol.2, n.2, p.56-77 jul./dez., 2018. 


\section{OO DEVIR EDUCAÇÃO}

ISSN: 2526-849X

pedagogical work of the teacher. The results indicate a strong induction effect that external evaluations and IDEB have produced in public schools and in education professionals, which involves issues such as goal setting, intense school monitoring and institutional replanning. Therefore, we have identified several uses and implications of IDEB and external evaluations, indicating that external evaluations modifiy school dynamics. The results corroborate the educational literature on the field.

Keywords: IDEB, external evaluations, educational management

\section{Introdução}

Pretendemos, neste artigo, analisar a percepção de gestores escolares sobre as avaliações externas e o Índice de Desenvolvimento da Educação Básica (IDEB), além de conhecer os efeitos que tal interface impõe às lógicas de gestão no nível das escolas em municípios mineiros 5 .

Nas últimas décadas, tem se assistido, no Brasil, a ascendência expressiva da utilização de avaliações sistêmicas pari passu a um movimento mais amplo, em escala mundial, que vem reconhecendo nas ferramentas de testagem e medidas de proficiência, estratégia privilegiada de gestão da educação, bem como de suposta promoção de sua qualidade.

Embora as primeiras tentativas de "medida-avaliação", no campo educacional brasileiro, remontem ao período de 1937-1945, correspondendo ao período do Estado Novo, pode-se dizer que o marco da criação de sistemas de avaliação educacional data de 1988, com a proposta de criação do Sistema de Avaliação do Ensino Público de Primeiro Grau (SAEP), apresentada ao MEC como contrapartida estipulada pelo Banco Mundial para o financiamento do Programa de Educação Básica para o Nordeste (FREITAS, 2007). Ainda que o SAEP não tenha conseguido ser implementado, especialmente, por razões orçamentárias, seus pressupostos e lógica levaram à criação do Sistema de Avaliação da Educação Básica (SAEB), formalizado em 1994 (BRASIL, 1994).

\footnotetext{
${ }^{5}$ Os sujeitos dessa pesquisa são egressos do Programa Nacional Escola de Gestores da Educação Básica (PNEG) na Universidade Federal de Ouro Preto (UFOP), uma das ações de formação de professores financiada pelo Ministério da Educação. Na UFOP, o programa foi implementado entre 2012 e 2017, certificando aproximadamente 1100 professores em 160 municípios do estado de Minas Gerais. Ofertado na modalidade a distância, o PNEG propõe aos cursistas a formulação e implementação de um projeto de intervenção nas unidades escolares onde atuam, dialogando com o projeto-político-pedagógico com vistas a fortalecer a gestão da escola em suas diversas dimensões.
} 


\section{QO DEVIR EDUCAÇÃO}

ISSN: 2526-849X

O SAEB, de base amostral, passou a coletar informações sobre o desempenho de alunos de $4^{\mathrm{a}}$ série $/ 5^{\circ}$ ano e $8^{\mathrm{a}}$ série $/ 9^{\circ}$ ano e do $3^{\circ}$ ano do ensino médio, nos componentes curriculares português e matemática, dando ênfase à leitura e interpretação e resolução de problemas. O exame tornou-se bianual a partir de 1995, quando foi alterada a metodologia que passou do modelo clássico à teoria de resposta ao item, permitindo a comparabilidade de resultados. O SAEB tem se configurado, de acordo com a categorização de Bonamino e Sousa (2012), uma avaliação de primeira geração ou low stake - de consequências leves. Pelo fato de o SAEB ser amostral, tal exame não permite a influência mais direta nas escolas por não contemplar medidas que estabeleçam correlação entre unidades escolares e desempenho de alunos, inviabilizando políticas de responsabilização, por exemplo.

Se o SAEB não teve potencial, por si, de adentrar as escolas, ele foi capaz de induzir a criação de sistemas próprios de avaliação, na esfera estadual, que, embora altamente tributários do modelo federal, sobretudo na adoção da escala avaliativa e de itens de teste, adotaram o desenho censitário. Atualmente, 13 estados brasileiros contam com iniciativas próprias de avaliação com programas de incentivos vinculados (SOUSA; KOSLINSKY, 2017), o que os situa na terceira geração de avaliações ou high stakes, por haver consequências de alto impacto, premiação ou punição em decorrência dos resultados alcançados pelas escolas (BONAMINO; SOUSA, 2012). Na esfera municipal, 1.573 municípios afirmaram, em levantamento por survey, ter proposta própria de avaliação da rede, o que representa $34,8 \%$ do total de municipalidades (FCC/INEP, 2016).

Aproximadamente uma década depois da formalização do SAEB, o governo federal cria, em 2005, a Prova Brasil, justificada pela necessidade de avaliar o desempenho escolar e pela existência de uma série de iniciativas estaduais de desenho censitário. Acompanhando o delineamento estadual, censitário, o teste passou a fornecer dados sobre escolas, redes, municípios, turmas, estados e país, o que permitiu à grande imprensa, de modo geral, divulgar os resultados do teste a partir de uma conduta alicerçada em comparações e constituição de rankings. Assim, buscou-se situar as avaliações externas como "solução para os problemas escolares", sem se por "a questão dessas avaliações, tal como são realizadas, em relação às finalidades da educação básica para o Brasil, em sua conjuntura” (GATTI, 2013, p. 58-59).

A Prova Brasil, exatamente por permitir a correlação entre redes, escolas, turmas e respectivos desempenhos cognitivos passa a ser situada como avaliações de segunda geração (BONAMINO; SOUSA, 2012), haja vista que a "divulgação pública dos resultados dessa 


\section{QO DEVIR EDUCAÇÃO}

ISSN: 2526-849X

avaliação pode funcionar como um elemento de pressão dos pais no sentido de adoção de providências para que a escola melhore" (BONAMINO, 2013, p. 50).

Com a institucionalização da Prova Brasil, o MEC foi capaz de construir o Índice de Desenvolvimento da Educação Básica (IDEB), em 2007, formulado a partir de indicador de fluxo e de desempenho médio naquela Prova, e a consequente estruturação de um conjunto de metas a serem alcançadas pelas escolas.

Do ponto de vista do planejamento e gestão educacionais, o IDEB passa a assumir grande centralidade no contexto do Plano de Metas "Compromisso Todos pela Educação", instituído em 2007 (BRASIL, 2007), que vincula a adesão dos entes federados à ação supletiva da União em relação às redes públicas de educação básica.

Com a avaliação externa em larga escala e o respectivo IDEB estruturando o "Compromisso Todos pela Educação", duas dimensões dos processos educacionais passaram a assumir novos contornos: de um lado, o IDEB foi definido como a "qualidade" em educação, restringindo-a dois indicadores que, salvo melhor juízo, longe estão da capacidade de expressar uma qualidade socialmente referendada e necessária à educação. De outro lado, passou-se a disseminar certa lógica de gestão delineada pelo governo central e assumida pelos estados e municípios que, no limite, perdem parte de sua autonomia federativa na medida em que sua capacidade decisória sobre os processos de gestão e políticas educacionais passam a ser definidas pelo centro e, por ele, também controladas remotamente.

Em relação ao planejamento, a Lei $n^{\circ} 13.005 / 2014$, que aprova o Plano Nacional de Educação (PNE) para a década, confirma esse lugar privilegiado do IDEB na gestão e política educacionais, uma vez que a meta sete reitera a tradução de qualidade educacional com o IDEB: "fomentar a qualidade da educação básica em todas as etapas e modalidades, com melhoria do fluxo escolar e da aprendizagem de modo a atingir as seguintes médias nacionais para o IDEB [...]" (BRASIL, 2014). A lógica que subjaz a essa “opção política” pode ser traduzida da seguinte forma: se o PNE é expressão de política de Estado e não de governo, o IDEB, ao ser inscrito como cabeça da meta do Plano, torna-se, pois, um instrumento de política de Estado.

De todo modo, o fato de iniciativas federais terem conseguido adentrar planos decenais, redes e escolas, na esfera dos entes subnacionais, fato esse explicado, sobretudo, pelas transferências voluntárias da União aos estados e municípios, não parece ser objeto de controvérsias nos estudos da área, levando-se a que se pergunte, inclusive, sobre uma possível 


\section{OO DEVIR EDUCAÇÃO}

ISSN: 2526-849X

recentralização da federação (ALMEIDA, 2005). Contudo, a interface dessas iniciativas de avaliação do âmbito federal com lógicas de gestão e políticas educacionais locais parece não se efetivar de modo linear como, a princípio, pode parecer. Ao que tudo indica, essa interação tem se dado por movimentos de acomodação, de resistência ou de "incorporação seletiva" (FREITAS; OVANDO, 2015), apontando tanto para a capacidade indutora/financeira da União quanto do espaço de discricionariedade exercida pela instância local.

Um dos "gargalos" nesse processo de interação, tradução ou assimilação dos municípios e estados, em relação ao governo federal, parece ser aquele relacionado a uma premissa básica, mas da qual decorrem equívocos substantivos em face de sua incompreensão. Trata-se da necessária distinção entre "medida" e as chamadas avaliações externas em larga escala.

A crítica especializada vem chamando atenção para esse aspecto que parece ter tido efeitos sobre as formas com que tais iniciativas vêm sendo compreendidas e assimiladas nas redes de ensino e escolas. Afinal, a "avaliação" em muito extrapola a "medida", que é uma das suas dimensões, sobretudo pelo fato de que a ela se associam juízos de valor sobre algo. Para se chegar à avaliação, a partir de determinada medida alcançada por testagem, é imperioso que se "reflita sobre seus significados e as possíveis ações a serem desenvolvidas a partir daí" (OLIVEIRA, 2013, p. 88).

É nesse sentido que tanto Oliveira (2013), quanto Viana (1999) apontam para os desdobramentos de "medidas-avaliações" nacionais em unidades subnacionais, ao afirmarem que "desta distinção decorre a importância de se refletir sobre as testagens em larga escala e a possibilidade de transformá-las em subsídios importantes para o processo avaliativo, tanto em nível de sistema quanto de unidade escolar" (OLIVEIRA, 2013, p. 88). O processo de avaliação somente poderá ser considerado como tal se os gestores dos sistemas educacionais e as escolas forem capazes de transformar os dados da realidade educacional, fornecidos pela testagem em larga escala, em ferramentas pedagogicamente relevantes e que tenham potencial para melhorar a gestão.

\section{IDEB, políticas públicas e gestão educacional}




\section{OO DEVIR EDUCAÇÃO}

ISSN: 2526-849X

Diversas são as ações implementadas pela União, estados e municípios com vistas a contribuir para a melhoria do desempenho das escolas e dos alunos. Dentre essas ações, a adoção de avaliações externas sistemáticas e periódicas é uma das estratégias para se alcançar tal objetivo. A criação do IDEB também pode ser considerada uma potente forma de estimular e fazer com que os sistemas estaduais e municipais de educação se mobilizem em torno daquele objetivo.

Segundo Vidal e Vieira (2011), as avaliações externas e o IDEB têm modificado o ambiente institucional das secretarias de educação, tanto no nível estadual quanto no nível municipal. O efeito indução aí identificado é fruto de um conjunto de transformações que tem sido potencializado a partir da promulgação da Constituição de 1988 e da LDBEN 9394/1996, quando assegura e institui que a gestão da educação é uma ação compartilhada pelos três entes federados, vinculando os subsistemas.

Oliveira e Sousa (2010) tratam da questão do federalismo e dos efeitos da descentralização no campo educacional sob diferentes óticas. Para os fins deste artigo, os autores destacam que as avaliações externas e o IDEB têm induzido modificações importantes na dinâmica municipal, especialmente em localidades pequenas e, portanto, altamente dependentes das transferências orçamentárias e dos programas financiados pelo governo federal. Nesse sentido, diversas são as pesquisas que têm destacado o efeito indução que tais avaliações e o IDEB têm produzido nos municípios e, consequentemente, nas escolas e no desempenho dos profissionais que nelas atuam. Ao assumir que a gestão escolar pode afetar o resultado do indicador, o foco recai sobre as unidades escolares e seus profissionais.

Segundo Freitas (2009), a avaliação é um instrumento de acompanhamento global de redes de ensino com o objetivo de traçar séries históricas de desempenho dos sistemas, que permitam verificar tendências ao longo do tempo, com a finalidade de reorientar políticas públicas e/ou programas de formação continuada. Brooke e Cunha (2011) avançam criticamente nessa direção quando afirmam que, mesmo com a evolução na qualidade das ações planejadas pelas secretarias de educação nas escolas - boletins pedagógicos, criação de um dia específico para o estudo coletivo do material devolutivo pela escola, a divulgação dos resultados - não asseguram automaticamente que os professores deles se apropriarão e/ou a eles estarão positivamente vinculados, com vistas à melhoria do desempenho. A partir dos resultados das avaliações externas, os autores afirmam que a formação continuada dos docentes é uma das estratégias para que essa convergência aconteça. Da mesma forma, 


\section{DEVIR EDUCAÇÃO}

ISSN: 2526-849X

defendem que ações voltadas para o monitoramento do desempenho dos alunos sejam implementadas a fim de produzir uma cultura sistêmica de acompanhamento. Nesse sentido, os autores citam o exemplo de Belo Horizonte, município que implantou o Programa de Monitoramento da Aprendizagem. Com base nos resultados das avaliações externas realizadas nessa rede, a Secretaria Municipal de Educação iniciou, em 2009, um acompanhamento sistemático e individualizado de todos os alunos do ensino fundamental. Além das ações voltadas para os alunos, como o reforço escolar, são também desenvolvidas ações de formação docente, em que os professores recebem formação específica e acompanhamento constante da Secretaria.

Brooke e Cunha (2011) também destacam o Plano de Intervenção Pedagógica (PIP), da Secretaria de Educação do Estado de Minas Gerais. Com base nos resultados das avaliações do Programa de Alfabetização, Documentação e Informação (PROALFA), educadores e gestores elaboram um PIP a fim de definir estratégias voltadas para melhorar o desempenho dos alunos. O objetivo é fazer com que as escolas com piores resultados recebam visitas de uma equipe pedagógica indicada especialmente para discutir e trabalhar pontualmente as lacunas observadas com os resultados das avaliações.

Bayer (2012), ao examinar como se dão os processos de tradução e interpretação de programas federais em instâncias locais, enfatizando o Plano de Desenvolvimento da Educação - Escola (PDE-Escola) em município do Paraná, afirma que no processo de efetivação das políticas que a escola recebe dos formuladores "surgem as dificuldades e a escola ao colocar essas políticas em ação, age conforme suas possibilidades e recursos" (BAYER, 2012, p. 132). Para a autora, as escolas tiveram que repensar seu planejamento, a partir do Programa PDE-Escola, mexendo com a dinâmica escolar e um dos aspectos relevantes, nesse contexto, foi o IDEB, uma vez que ele "pode ser um ponto de partida para ajudar a pensar nas possibilidades de encaminhar políticas mais próximas às necessidades de cada contexto" (BAYER, 2012, p. 135).

Freitas e Ovando (2015), em pesquisa que investigou dez redes escolares no estado do Mato Grosso do Sul que se destacavam no IDEB, trazem nos seus achados de pesquisa, pelo menos, duas estratégias mobilizadas pelas municipalidades, na articulação com iniciativas federais de medida e avaliação: os municípios incorporaram à sua gestão e planejamento procedimentos seletivos e de adaptação das diretrizes nacionais, expressando forma peculiar de colaboração com a União. Ademais, a interface com os desenhos avaliativos federais levou 


\section{QO DEVIR EDUCAÇÃO}

ISSN: 2526-849X

os municípios a construírem ferramentas incipientes de avaliação. As autoras concluíram que o uso da avaliação está orientado para a regulação, a indução e, raramente, para as funções diagnóstica, formativa ou de prestação de contas pública.

As redes municipais de ensino do Rio Grande do Sul e a forma como se articulam frente às avaliações externas foram objeto de problematização de Werle (2013). Nas redes pesquisadas, a autora encontrou evidências de que os gestores locais cuidaram de criar iniciativas próprias de avaliação em estreita relação com o modelo federal, reconhecendolhes, inclusive, a sistemática e dados produzidos, de um lado. Já de outro, buscou-se criar um “eixo participativo e de valorização das práticas pedagógicas dos docentes" (WERLE, 2013, p. 280-209). O trabalho de Werle (2013) ainda aponta para desdobramentos das iniciativas locais de avaliação e políticas de remuneração docente que teria levado à interrupção, ainda que temporária, das avaliações municipais, por terem encontrado resistência dos profissionais da educação.

Já a pesquisa de Vidal e Vieira (2011), realizada em dez municípios do Ceará, levaram as autoras a afirmar que o IDEB se tornou elemento "norteador, por excelência, da política municipal de educação dos municípios", fazendo com que sua gestão esteja relacionada à melhoria do índice nas escolas. Esse movimento, segundo Vidal e Vieira, induziu a processo de monitoramento intenso nas escolas, pelas Secretarias Municipais de Educação. Ainda segundo as autoras, a investigação traz evidências que as políticas municipais são dependentes das estaduais e federais, tanto no seu planejamento quanto na orçamentária (VIDAL; VIEIRA, 2011, p. 430).

\section{Método}

No total, participaram cinco escolas públicas de quatro municípios do estado de Minas Gerais, todas elas atendidas pelo PNEG na UFOP: Itabira, João Monlevade, Ouro Preto e Mariana. A Tabela 1 apresenta alguns dados contextuais das escolas investigadas (Tabela 1) porque o contexto educacional de cada instituição pode influenciar as percepções das gestoras em relação ao IDEB e às avaliações externas. Os indicadores selecionados foram: o IDEB; 


\section{QO DEVIR EDUCAÇÃO}

ISSN: 2526-849X

Percentual de Docentes com Curso Superior; Adequação da Formação Docente; Nível Sócio Econômico da Escola; Complexidade de Gestão da Escola; Regularidade do Corpo Docente.

Como apontado na Tabela 1, todas as escolas apresentam valores altos do IDEB dos anos iniciais do ensino fundamental, sendo que três já atingiram a um IDEB igual a seis estabelecida pelo governo federal para o ano de 2022. A única exceção é a escola C, que apresenta um IDEB baixo para os anos finais. Quanto ao percentual de docentes com curso superior, a escola E apresenta o percentual mais baixo $(86,7 \%)$ nos anos iniciais. Já a adequação da formação docente apresenta cinco grupos, sendo o grupo 1 aquele considerado “ideal". Nos anos iniciais, a escola C $(47,1 \%)$ e a escola A $(60,6 \%)$ apresentam os percentuais mais baixos, respectivamente, de docentes com formação superior de licenciatura (ou bacharelado com complementação pedagógica) na mesma área da disciplina que lecionam. Chama atenção a situação da escola $\mathrm{E}$, que apresenta $14 \%$ de docentes sem formação superior. Nos anos finais, as escolas B $(61,5 \%)$ e C $(63,9 \%)$ apresentam percentuais considerados baixos no grupo 1 .

O nível socioeconômico das escolas é favorecido, pois nenhuma das instituições consta nas classificações de estratos considerados mais baixos. Com relação à complexidade de gestão da escola, as escolas C e D apresentam o nível seis, considerado como a maior complexidade possível (escolas que, em geral, possuem porte superior a 500 matrículas, funcionam em três turnos, com oferta de quatro ou mais etapas de ensino e apresentam a EJA como etapa mais elevada). A escola B também pode ser considerada de maior complexidade (nível quatro), enquanto as escolas A e E apresentam complexidade mais baixa. As escolas A e B apresentam o corpo docente com maior rotatividade, pois, segundo esse indicador, quanto mais próximo de zero, mais irregular é o vínculo do docente com a escola. Adicionalmente, um dado relevante que não foi incluído na Tabela 1: a escola $\mathrm{C}$ apresenta as taxas mais altas de reprovação (dados de 2016): $23,1 \%$ no $3^{\circ}$ ano, $29,5 \%$ no $5^{\circ}$ ano e $29 \%$ no $6^{\circ}$ ano. Vale ainda mencionar a taxa de reprovação de $18,2 \%$ da escola B no $9^{\circ}$ ano. Portanto, tomados em conjunto, esses indicadores nos mostram escolas com realidades heterogêneas (com exceção do nível socioeconômico e de um IDEB alto para os anos iniciais). A escola com o contexto mais desfavorecido é a escola $\mathrm{C}$, pois acumula a maior quantidade de indicadores nesse sentido: baixo IDEB para os anos finais, baixa adequação da formação docente, complexidade de gestão muito elevada e taxas altas de reprovação.

Revista Devir Educação, Lavras, vol.2, n.2, p.56-77 jul./dez., 2018. 


\section{OO DEVIR EDUCAÇÃO}

ISSN: 2526-849X

Realizamos entrevistas semiestruturadas individualmente com cinco gestoras egressas do PNEG na universidade: Carla, Escola A, Itabira; Maria, Escola B, João Monlevade; Rosana, Escola C, Ouro Preto; Michele, Escola D, Mariana; Patrícia, Escola E, Mariana ${ }^{6}$. Todas as entrevistas foram gravadas em áudio e transcritas. Após a transcrição, selecionamos excertos que abordavam prioritariamente o IDEB e sua relação com a gestão.

Utilizamos uma abordagem qualitativa, que favorece o trabalho com os significados que os sujeitos dão às coisas e situações. Para a análise dos dados, usamos a análise de conteúdo, um método que "pode se aplicar a uma grande diversidade de materiais, como também permite abordar uma diversidade de objetos de investigação: atitudes, valores, representações, mentalidades, ideologias, etc.” (LAVILLE; DIONNE, 1999, p. 215). Gall, Gall e Borg (2007) sugerem as seguintes etapas na análise de conteúdo: 1) especificar as questões de pesquisa, hipóteses ou objetivos; 2) selecionar uma amostra de documentos para analisar; 3) desenvolver um procedimento de categorização-codificação; 4) codificar os dados; 5) interpretar os resultados.

A categorização se caracteriza pela separação e reagrupação dos dados em categorias de análise, por meio de aspectos comuns. A categorização tem como função mais importante "fornecer por condensação, uma representação simplificada dos dados em bruto" (BARDIN, 2009, p. 147). Utilizamos o processo de categorização denominado por caixas, que acontece quando as categorias já são previamente definidas e o pesquisador distribui os dados entre elas (BARDIN, 2009). Nesse sentido, empregamos as seguintes categorias analíticas: a) modificação da gestão escolar; b) IDEB e qualidade em educação; c) modificação do trabalho pedagógico do professor.

\footnotetext{
${ }^{6}$ Todos os nomes utilizados aqui são fictícios.
}

Revista Devir Educação, Lavras, vol.2, n.2, p.56-77 jul./dez., 2018. 


\section{ISSN: 2526-849X}

Tabela 1 - Indicadores educacionais das escolas

\begin{tabular}{|c|c|c|c|c|c|c|c|c|c|c|c|c|c|c|c|c|c|c|}
\hline \multirow[b]{2}{*}{ Município } & \multirow[b]{2}{*}{ Escola } & \multicolumn{2}{|c|}{ IDEB 2015} & \multicolumn{2}{|c|}{$\begin{array}{c}\% \text { Docentes } \\
\text { Curso Superior }\end{array}$} & \multicolumn{5}{|c|}{$\begin{array}{c}\text { Adequação da Formação } \\
\text { Docente }\end{array}$} & \multicolumn{5}{|c|}{$\begin{array}{l}\text { Adequação da Formação } \\
\text { Docente }\end{array}$} & \multirow[b]{2}{*}{$\begin{array}{c}\text { NSE } \\
(2013)\end{array}$} & \multirow[b]{2}{*}{$\begin{array}{c}\text { CGE } \\
(2016)\end{array}$} & \multirow[b]{2}{*}{$\begin{array}{c}\text { RCD } \\
(2016)\end{array}$} \\
\hline & & $\begin{array}{l}\text { Anos } \\
\text { iniciais }\end{array}$ & $\begin{array}{l}\text { Anos } \\
\text { finais }\end{array}$ & $\begin{array}{l}\text { Anos } \\
\text { iniciais }\end{array}$ & $\begin{array}{l}\text { Anos } \\
\text { finais }\end{array}$ & G1 & $\mathrm{G} 2$ & G3 & G4 & G5 & G 1 & $\mathrm{G} 2$ & G3 & G4 & G 5 & & & \\
\hline Itabira & A & 6,3 & -- & 100 & -- & 60,6 & 0,0 & 39,4 & 0,0 & 0,0 & -- & -- & -- & -- & -- & $\begin{array}{l}\text { Médio } \\
\text { Alto }\end{array}$ & $\begin{array}{c}\text { Nível } \\
3\end{array}$ & 2,7 \\
\hline $\begin{array}{c}\text { João } \\
\text { Monlevade }\end{array}$ & B & 6,4 & 5,5 & 100 & 100 & 100 & 0,0 & 0,0 & 0,0 & 0,0 & $\begin{array}{c}61 \\
5\end{array}$ & 0,0 & $\begin{array}{c}28, \\
2\end{array}$ & $\begin{array}{c}10, \\
3\end{array}$ & 0,0 & Alto & $\begin{array}{c}\text { Nível } \\
4\end{array}$ & 2,8 \\
\hline Ouro Preto & $\mathrm{C}$ & 5,4 & 3,6 & 100 & 100 & 47,1 & 0,0 & 0,0 & 52,9 & 0,0 & $\begin{array}{c}63 \\
9\end{array}$ & 0,0 & $\begin{array}{c}19 \\
4\end{array}$ & $\begin{array}{c}16 \\
7\end{array}$ & 0,0 & $\begin{array}{l}\text { Médio } \\
\text { Alto }\end{array}$ & $\begin{array}{l}\text { Nível } \\
6\end{array}$ & 3,8 \\
\hline Mariana & $\mathrm{D}$ & 6 & -- & 93,5 & -- & 79,2 & 0,0 & 15,0 & 0,0 & 5,8 & -- & -- & -- & -- & -- & Médio & $\begin{array}{l}\text { Nível } \\
6\end{array}$ & 3,8 \\
\hline Mariana & $\mathrm{E}$ & 5,8 & -- & 86,7 & -- & 72,0 & 0,0 & 7,0 & 7,0 & 14 & -- & -- & -- & -- & -- & $\begin{array}{l}\text { Médio } \\
\text { Alto }\end{array}$ & $\begin{array}{c}\text { Nível } \\
2\end{array}$ & 3,9 \\
\hline
\end{tabular}

Fonte: elaboração própria a partir dos dados do INEP

Nota: NSE = Nível Sócio Econômico da Escola; CGE= Complexidade de Gestão da Escola; RCD= Regularidade do Corpo Docente. Para maiores detalhes sobre as categorias de adequação da formação docente e os níveis de complexidade de gestão ver http://portal.inep.gov.br/web/guest/indicadores-educacionais. 


\section{Análise e discussão das entrevistas}

\section{Modificação da gestão escolar}

Essa categoria enfatiza as modificações que o IDEB tem induzido na gestão escolar, associada à promoção de mudanças na prática do gestor para tentar melhorar o aprendizado e/ou se adaptar a exigências externas. Algumas modificações na gestão identificadas nas entrevistas foram: elaboração de plano de ação escolar (estabelecendo metas a serem atingidas), discussão sobre os resultados em reuniões com os professores, reflexão sobre as práticas pedagógicas da escola, identificação de aspectos pedagógicos ou da matriz curricular que podem ser aperfeiçoados, revisão do Projeto Político Pedagógico da escola:

analisamos os gráficos, nós vemos os avanços da escola e o que precisa melhorar. Dentro dessa avaliação que fizemos em conjunto numa reunião pedagógica, nós traçamos um novo plano de trabalho. Eu acho que ele direciona a qualidade da gente e é um parâmetro para ver o que precisamos aperfeiçoar (Carla, Escola A, Itabira).

É interessante porque mobiliza para mais, para melhor. Quando a gente pega o resultado, analisa: "mas por que caiu? O que aconteceu? Por que melhorou?" Então salvo do MEC esses resultados, se alcançamos aquela projeção ou não. A gente faz uma reunião pedagógica para mostrar esse resultado, para analisar, para pegar a matriz de referência da prova, ver quais questões que os alunos tiveram maiores erros (Maria, Escola B, João Monlevade).

A gente pega os resultados, mostra para os professores e faz uma avaliação do que pode tentar melhorar, quais foram as dificuldades encontradas. Normalmente se faz isso, um estudo em cima da proficiência. As coisas que a gente foi mudando, a estrutura do trabalho, a questão desse acompanhamento do $1^{\circ}$ ao $3^{\circ}$ ano, as metas que a gente sabe que tem que alcançar, a busca de novas formas dos alunos conseguirem vencer as dificuldades, é o resultado (Rosana, Escola C, Ouro Preto).

O IDEB faz parte da rotina da escola. As provas externas fazem parte do dia a dia. Hoje, inclusive, o município avalia. A gente teve que rever essas questões todas (PPP), é tudo muito detalhado e cansativo pra gente. A gente teve que pegar esses resultados, tivemos que fazer cálculo. Tivemos que traçar metas, mas não foi um processo que foi concluído, mas foi válido. 


\section{QO DEVIR EDUCAÇÃO}

ISSN: 2526-849X

Porque você visualizar o que se quer, no sentido de traçar metas (Michele, Escola D, Mariana).

O resultado do IDEB, apesar de já ser o final da linha, traz o que a gente tem feito e tem dado resultado e o que não. Com o resultado a gente faz a nossa programação. Até então, cada escola fazia o seu planejamento anual. A partir da matriz, não. Você tem determinado bimestralmente, você tem as capacidades que são determinantes para cada série, que têm que ser cumpridas ao final do ano. A gente passa em todas as escolas da rede para ter a mesma direção. Hoje, até os tipos de texto que são trabalhados são os mesmos em todas as escolas (Patrícia, Escola E, Mariana).

Conforme já destacado, muitas pesquisas mostram o efeito indução que as avaliações externas e o IDEB têm produzido nas escolas e nos profissionais que nelas atuam (OLIVEIRA; SOUSA, 2010). Isso fica muito claro na percepção das gestoras entrevistadas, com afirmações como "ele direciona a qualidade da gente. E ao mesmo tempo é um parâmetro" (Carla) "ele é interessante no sentido de que mobiliza" (Maria). A consequência dessa indução é o estabelecimento de metas, evidenciadas em trechos como "as metas que a gente sabe que tem que alcançar" (Rosana) e "Válido no sentido de que, de você visualizar o que você quer, no sentido de traçar metas" (Michele). Tudo isso revela uma indução de um processo de monitoramento intenso nas escolas (VIDAL; VIEIRA, 2011), com discussão sobre os resultados em reuniões com os professores, reflexão sobre as práticas pedagógicas da escola e revisão do Projeto Político Pedagógico. São exemplos as falas: "a gente faz uma reunião pedagógica pra fazer uma análise desse resultado" (Maria), "Normalmente se faz isso, um estudo em cima da proficiência" (Rosana). Portanto, as escolas têm que repensar seu planejamento, mexendo com a dinâmica institucional (BAYER, 2012, p. 135). E isso já é visto inclusive de maneira natural, quando Michele afirma: "o IDEB faz parte da rotina da escola".

Ainda que as escolas pesquisadas possuam complexidade de gestão heterogêneas (as escolas C e D apresentam o nível maior de complexidade, enquanto as escolas A e E apresentam uma complexidade mais baixa), isso não se refletiu em percepções diferentes das gestoras, que relatam modificações muito parecidas na gestão escolar.

\section{IDEB e qualidade em educação}

Revista Devir Educação, Lavras, vol.2, n.2, p.56-77 jul./dez., 2018. 


\section{DEVIR EDUCAÇÃO}

ISSN: 2526-849X

Essa categoria enfatiza a ideia do IDEB como o definidor de um padrão de qualidade educacional e a consequente estruturação de um conjunto de metas a serem alcançadas pelas escolas. Ou seja, está associada com o lugar privilegiado do IDEB na gestão e política educacionais, uma vez que esse índice é visto como a tradução de qualidade educacional.

Um dos aspectos presentes no conjunto das entrevistas relaciona-se a não vinculação, na percepção das gestoras, de IDEB e padrão de qualidade educacional:

É uma ferramenta para gente ver o que pode melhorar. Mas falar que é padrão de qualidade eu fico um pouquinho receosa. É uma ferramenta a mais pra gente tentar melhorar o ensino. Mas que ela é um padrão de qualidade eu não concordo (Rosana, Escola C, Ouro Preto).

A Secretaria está muito focada nos resultados. O IDEB gera um incômodo, quando você não está dentro de um padrão, e acho que é positivo no sentido de mudança de comportamento. Se isso me incomoda, então o que eu posso fazer para mudar? Se eu pegar provas de nove anos atrás e as de hoje eu vejo qualitativamente que há uma diferença em termos de qualidade. E eu atribuo isso ao IDEB? Não. Por exemplo, um fator que fez diferença em termos de qualidade, em termos de aprendizagem e que os professores gostaram foi o Pacto (Michele, Escola D, Mariana).

No entanto, nesses exemplos, as gestoras também reconhecem aspectos positivos do IDEB. Rosana diz que "é uma ferramenta a mais pra gente tentar melhorar o ensino". Michele também concorda com essa "indução positiva" quando afirma: "o que eu posso fazer para poder mudar. Onde é que eu posso melhorar". Ambas também reconhecem que outros fatores influenciam a qualidade. Michele, por exemplo, atribui melhorias na qualidade educacional em função da participação dos professores no PNAIC. Apesar de não concordarem com o IDEB como "o padrão" de qualidade, as entrevistadas também não adotam uma postura mais radical de que o IDEB "não mede nada". Em outro exemplo nesse sentido, Carla, da Escola A, diz "ele vai interferir sim porque assim, mostra a realidade da escola. Não é?". Uma fala um pouco mais crítica foi da gestora Patrícia da Escola E: "Porque ele (IDEB) está muito mais pra ranquear do que pra te apontar qualidade". Vale ainda destacar que as escolas investigadas nessa pesquisa apresentam de maneira geral um IDEB 


\section{DEVIR EDUCAÇÃO}

ISSN: 2526-849X

considerado alto (Tabela 1). Uma hipótese a ser testada em pesquisas futuras é se isso influencia uma percepção mais positiva do IDEB.

Outra questão importante que apareceu nas entrevistas foi um entendimento mais amplo sobre os resultados do IDEB:

À medida que ele homogeneíza, coloca todo mundo dentro da mesma caixinha, sem considerar as especificidades de escola, de aluno. Ele não dá conta das especificidades. Eu acho que é um parâmetro interessante. Mas não acredito que possa ser considerado só ele. Eu não posso dizer que uma escola é boa ou ruim só pelo IDEB. A gente precisa conhecer os processos da escola, o contexto social em que ela está inserida. Eu acho muito complexo que ele é um padrão de qualidade, porque eu acho que não. Acho que o IDEB não dá conta desse contexto todo (Maria, Escola B, João Monlevade).

Só que aí tinha aquelas escolas pequenas, que atendem a uma clientela um pouco melhor em termos de acompanhamento de pais, de tudo, e tinha um resultado sempre melhor. Eu acho que se você for falar da questão da clientela, que ela tenha mais condições -são crianças que tem mais acesso à leitura em casa -aí sim. Está vendo que a gente tá conseguindo, a gente tá elevando, a gente não está com resultado que determinada escola está, mas olha o nosso histórico, olha a nossa evolução (Rosana, Escola C, Ouro Preto).

As falas das gestoras sinalizam para um aspecto bastante discutido na literatura: o IDEB foca em resultados finalísticos sem levar em consideração as condições específicas de produção desses resultados. Assim, é importante considerar o IDEB juntamente com as condições contextuais das escolas, o que envolve tanto o perfil dos estudantes quanto as características das instituições escolares (ALVES; SOARES, 2013). Isso fica claro quando, por exemplo, Maria afirma que "a gente precisa conhecer os processos da escola, o contexto social, em que ela está inserida". Ou quando Rosana diz que "só que aí tinha aquelas escolas pequenas, que atendem a uma clientela um pouco melhor em termos de acompanhamento de pais, de tudo, e tinha um resultado sempre melhor". Escolas menores significam escolas menos complexas do ponto de vista da gestão, sendo que Rosana pertence justamente a uma das escolas da amostra que apresentam o nível máximo de complexidade de gestão. Por fim, conhecer o contexto é fundamental para escolas com realidades muito diferentes não sejam comparadas, o que é considerado injusto. Rosana indica esse aspecto apontado na literatura, quando foca em uma comparação dos resultados da sua própria escola: "a gente não está com

Revista Devir Educação, Lavras, vol.2, n.2, p.56-77 jul./dez., 2018. 


\title{
OO DEVIR EDUCAÇÃO
}

ISSN: 2526-849X

resultado que determinada escola está, mas olha o histórico nosso, olha a evolução nossa".

Um último ponto importante dessa categoria que aparece nas entrevistas é a questão da garantia do direito à educação previsto na Constituição:

\begin{abstract}
A gente precisa trabalhar e garantir o direito de aprender que essas crianças têm. Nós estamos aqui porque existem alunos e eles têm direito de aprendizagem. O objetivo dele, mais do que medir, é mobilizar também. Existe uma avaliação que está considerando capacidades básicas, mínimas. E por que as crianças não estão dando conta das capacidades básicas e mínimas? Em que patamar está o trabalho da escola que não está conseguindo garantir isso? (Maria, Escola B, João Monlevade).

Porque a habilidade de compreender, a compreensão leitora, a capacidade de escrever, ela vem a partir do momento em que o aluno lê. Precisa ter essa compreensão bem desenvolvida. E que isso não é só uma competência da língua portuguesa. Isso é algo que tem que ser trabalhado por todas as matérias (Michele, Escola D, Mariana).
\end{abstract}

Aqui, mais uma vez, podemos refletir sobre o IDEB como um indicador de educação de qualidade. Maria aponta que "a gente precisa trabalhar e garantir o direito de aprender que essas crianças têm", enquanto Michele diz que a competência da língua portuguesa "é algo que tem que ser trabalhado por todas as matérias". Elas reconhecem que o direito à educação só se concretiza quando o estudante aprende na idade adequada. Nesse sentido, apesar de todas as críticas, esse foi um ponto positivo: a incorporação do aprendizado dos alunos no monitoramento das escolas (SOARES; XAVIER, 2013). Essa é umas das principais justificativas para a existência de um índice como o IDEB e também para avaliações externas: o direito à educação passa a envolver não só a garantia do acesso e da permanência, mas também a garantia de um padrão de qualidade (OLIVEIRA; ARAUJO, 2005).

\section{Modificação do trabalho pedagógico do professor}

Essa categoria enfatiza as modificações que o IDEB tem induzido no trabalho pedagógico do docente. Está associada com uma promoção de mudanças na prática do professor para tentar melhorar o aprendizado e/ou se adaptar a exigências externas. Uma das 


\section{OO DEVIR EDUCAÇÃO}

ISSN: 2526-849X

modificações no trabalho pedagógico identificadas nas entrevistas foram alterações na forma dos professores avaliarem a aprendizagem dos alunos:

Seriam cobradas, não como uma forma de treinamento. A gente não faz isso. Eu vou ser bem clara: nunca me preocupei muito em treinar para prova. Eu acho que tem escolas que têm essa prática (Maria, Escola B, João Monlevade).

A partir do momento que foram chegando as avaliações a gente foi mudando o nosso olhar sobre como trabalhar com o aluno. As primeiras foram uma tragédia grega, porque aluno não sabia marcar o $\mathrm{x}$, marcava em tudo (Rosana, Escola C, Ouro Preto).

Trabalhar com esses dados, a gente vem aprendendo ao longo do tempo. Porque você precisa ter uma noção exata do que é uma habilidade, o que é uma capacidade, como é que elas conversam. O que eu tenho pedido é que em todas as provas, não só nas provas, mas nas atividades na sala, tenha textos. Eu tenho exigido mesmo. Os alunos também não estavam muito acostumados com provas fechadas, não sabiam marcar direito. Aí os professores começaram a fazer provas no formato para eles também aprenderem. Não sabia nem usar gabarito (Michele, Escola D, Mariana).

Enquanto Maria diz que não se preocupa em treinar para a prova externa (apesar de reconhecer que muitas escolas fazem isso), tanto Rosana quanto Michele relatam alterações na forma de avaliação de sala de aula com o intuito de adaptação dos alunos e consequente otimização de resultados, como inclusão de textos e de questões de múltipla escolha nas provas. Outro fenômeno comum relatado na literatura é a realização de provas simuladas.

Outras modificações do trabalho pedagógico docente presentes nas entrevistas foram: diversificação de atividades pedagógicas dos professores, discussão dos resultados com os alunos, planejamento de atividades de acordo com as matrizes de referência da avaliação externa.

Nós separamos uma parte da nossa aula e uma vez por semana, ou de acordo com o desenvolvimento da turma, a gente já especifica para trabalhar justamente aquelas questões que não estamos avançando. A gente faz um trabalho paralelo ao livro didático e ao planejamento rotineiro que a gente tem. Quando a gente vê que tem alguma coisa que trabalhamos e não está sendo assimilado pelo aluno, é sinal de que tem que voltar, rever o trabalho. E continuar (Carla, Escola A, Itabira). 


\section{OO DEVIR EDUCAÇÃO}

ISSN: 2526-849X

As avaliações têm esse caráter de redimensionar a prática. Eu não posso ir participar de avaliação e ficar do mesmo jeito (Maria, Escola B, João Monlevade).

Quando chega o resultado do $3^{\circ}$ ano, eles estão no $4^{\circ}$. Um resultado que a gente consegue rápido é o da Provinha Brasil. Porque ele faz a avaliação, faz a correção e ali dá pra ver quais são os níveis que os alunos estão e o que deve ser trabalhado. Dá tempo. Agora, esses outros, tanto do $3^{\circ}$ quanto do $5^{\circ}$ ano, quando a gente recebe, os meninos já estão em outras turmas (Rosana, Escola C, Ouro Preto).

Esse trabalho com esses meninos que a gente identifica como baixo desempenho é muito mais cuidadoso do que era antes. Porque até então os nossos registros também não eram muito bons, precisam melhorar. Mas em relação ao que era está bem legal (Patrícia, Escola E, Mariana).

Aqui, Carla menciona um "trabalho paralelo ao livro didático e ao planejamento rotineiro" para se adequar aos resultados das avaliaçoes externas e inclusive o fato de que toda a equipe está imbuída da ideia de melhorar o "índice”. Maria diz claramente que "as avaliações têm esse caráter de redimensionar a prática". Rosana aponta um aspecto importante e também discutido na literatura: o atraso com o qual alguns resultados de avaliações externas chegam à escola. Isso dificulta a diversificação e o planejamento de atividades pedagógicas dos professores em função dos resultados dos alunos. Já Patrícia indica que essa indução externa nem sempre é ruim, sinalizando que "esse trabalho com esses meninos que a gente identifica como baixo desempenho é muito mais cuidadoso do que era antes". Ela percebe uma mudança positiva quando compara o antes e o depois das avaliações externas.

Por fim, também identificamos o uso dos resultados como critérios para formação de grupos de alunos:

Pro Programa de Intervenção, ele tem ficado mais em sala de aula com atividades em grupos e atende as crianças em grupos. Quando saem resultados, a gente procura identificar, geralmente você consegue ver ali qual a capacidade que houve maior número de erros e a gente procura trabalhar em cima dessa capacidade (Maria, Escola B, João Monlevade). 


\section{OO DEVIR EDUCAÇÃO}

ISSN: 2526-849X

Nesse caso, Maria se refere ao PIP, que gera modificações do trabalho pedagógico usando resultados de avaliações para agrupar alunos e trabalhar a partir dos erros identificados.

\section{Considerações finais}

Em síntese, os resultados apontam para um forte efeito de indução que as avaliações externas e o IDEB têm produzido nas escolas e nos profissionais da educação, o que envolve questões como o estabelecimento de metas, monitoramento intenso das escolas e replanejamento institucional. Portanto, há diversos usos e implicações do IDEB e das avaliações externas que corroboram a literatura educacional.

Segundo Voss e Garcia (2014), como a escola emerge como espaço estratégico nesse processo, os atores que nela trabalham passam a incorporar a gramática do desempenho em suas rotinas, influenciando seus comportamentos, atitudes, percepções e estratégias de atuação. No que se refere à dinâmica das avaliações externas e do IDEB, os profissionais da escola - diretores, equipe pedagógica, professores e equipe administrativa - são os agentes públicos que, em maior ou menor grau, traduzirão e implementarão as ações desenhadas no nível estratégico pelos diversos governos com vistas à elevação do desempenho de seus alunos e suas escolas, induzidas - ou não - pelas avaliações externas e/ou pelo IDEB.

Para Ivo e Hypolito (2015), tal cultura avaliativa tem produzido uma reorganização do espaço escolar. Muitas ações, oriundas de órgãos nacionais, estaduais e municipais têm imprimido um novo formato à gestão escolar, repercutindo na redefinição das rotinas, dos tempos e das tarefas inerentes ao trabalho docente. Entretanto, são diferenciadas as interpretações que os educadores fazem das mesmas, vez que há, segundo Miranda (2014), diversos elementos que influenciam esse processo. Há, portanto, um distanciamento entre o contexto da prática e da política, razão pela qual importa entender como os profissionais da educação interpretam a política tendo por base a realidade sócio-histórico-cultural em que cada escola está inserida. 


\section{OO DEVIR EDUCAÇÃO \\ ISSN: 2526-849X}

\section{Referências}

ALMEIDA, Maria Hermínia Tavares de. Recentralizando a federação? Revista de Sociologia Política, Curitiba, n. 24, p. 29-40, jun. 2005.

ALVES, Maria Teresa Gonzaga; SOARES, José Francisco. Contexto escolar e indicadores educacionais: condições desiguais para a efetivação de uma política de avaliação educacional. Educação e Pesquisa, v. 39, n. 1, p. 177-194, 2013.

BARDIN, Laurence. Análise de conteúdo. Lisboa, Portugal: Edições 70, 2009.

BAYER, Mariana Ferreira. O Programa PDE Escola: uma análise da sua implementação em Guarapuava - PR. Dissertação (Mestrado em Educação). Universidade Estadual de Ponta Grossa, Ponta Grossa, 2012.

BRASIL. Lei n.13.005, de 25 de junho de 2014. Aprova o Plano Nacional de Educação PNE e dá outras providências. Diário Oficial da União, Brasília, DF, 2014.

BRASIL. Decreto n. 6.094, de 24 de abril de 2007. Dispõe sobre a implementação do Plano de Metas Compromisso Todos pela Educação. Brasília, DF, 2007.

BONAMINO, Alicia. Avaliação educacional no Brasil 25 anos depois: onde estamos? In: BAUER, Adriana; GATTI, Bernardete. (Orgs.). Vinte e cinco anos de avaliação de sistemas educacionais no Brasil: implicações nas redes de ensino, no currículo e na formação de professores. Florianópolis: Insular, 2013. p 43-60.

BONAMINO, Alicia; SOUSA, Sandra. Zákia. Três gerações de avaliação da educação básica no Brasil: interfaces com o currículo da/na escola. Educação e Pesquisa, São Paulo, v. 38, n. 2, jun. 2012.

BROOKE, Nigel. CUNHA, Maria. Amália. A avaliação externa como instrumento da gestão educacional nos estados. Belo Horizonte, Editora UFMG, 2011.

FREITAS, Dirce Nei Texeira de. A avaliação da educação básica no Brasil. Campinas: Autores Associados, 2007.

FREITAS, Dirce Nei Teixeira de; OVANDO, Nataly Gomes. A avaliação educacional em contextos municipais. Educação \& Sociedade, Campinas, v. 36, n. 133, p. 963-984, dez. 2015.

GALL, Meredith; GALL, Joyce; BORG, Walter. Educational research: an introduction. New York: Pearson, 2007. 672 p.

GATTI, Bernardete. Possibilidade e Fundamentos de Avaliações em Larga Escala: Primórdios e Perspectivas Contemporâneas. In: BAUER, Adriana; GATTI, Bernardete. 


\section{Q DEVIR EDUCAÇÃO \\ ISSN: 2526-849X}

(Orgs.). Vinte e cinco de avaliação de sistemas educacionais no Brasil: origens e pressupostos. Florianópolis: Insular, 2013. p 47-69.

LAVILLE, Christian; DIONNE, Jean. Em Busca de Informações. In: A construção do saber: manual de metodologia da pesquisa em ciências humanas. Belo Horizonte: Editora UFMG, 1999, p. 165-196.

FREITAS, Luís. Carlos. Avaliação educacional: caminhando pela contramão. Rio de Janeiro: Vozes, 2009.

GARCIA, Ana Lúcia. Gestão da escola, qualidade de ensino e avaliação externa: desafios na e da escola. Unesp, Marília, 2010

IVO, Andressa; HYPOLITO, Àlvaro. Gestão educacional e o índice de desenvolvimento da educação básica da rede municipal de ensino de santa maria - Rio Grande do Sul. Revista Educação em Questão, Natal, v. 52, n. 38, p. 163- 192, 2015.

MIRANDA, Estela. Contribuciones de Stephen Ball a la investigación sobre políticas educacionales como campo teórico. II Jornadas Latinoamericanas em Estudios Epistemológicos em Política Educativa. 2014. Curitiba. Paraná.

OLIVEIRA, Romualdo Portela; SOUSA, Sandra Sákia. Introdução. In: SANTANA, Wagner (Orgs.). Educação e federalismo no Brasil: combater as desigualdades, garantir a diversidade. Brasília: Unesco, 2010.

OLIVEIRA, Romualdo Portela. A utilização de indicadores de qualidade na unidade escolar ou porque o IDEB é insuficiente. In: BAUER, Adriana; GATTI, Bernadete.; TAVARES, Marialva. (Org.). Vinte e cinco anos de avaliação de sistemas educacionais no Brasil: implicações nas redes de ensino, no currículo e na formação de professores. Florianópolis: Insular, 2013. p. 87-100.

OLIVEIRA, Romualdo Portela; ARAUJO, Gilda Cardoso. Qualidade do ensino: uma nova dimensão da luta pelo direito à educação. Revista Brasileira de Educação, n. 28, p. 5-24, 2005 .

PIERSON, Paul. Fragmented Welfare States: Federal Institutions and the Development of Social Policy. Governance: International Journal of Policy and Administration, London, v. 8, n. 4, p. 449-478, Oct, 1995.

POLATO, Amanda. A relação entre as avaliações em larga escala e a organização do trabalho escolar em duas escolas públicas estaduais do interior de São Paulo. Dissertação (Educação). Universidade Estadual Paulista Júlio de mesquita. Rio Claro, 172 f. 2014.

SILVA, Maria Juliana de Almeida. Regulação educativa: o uso dos resultados de proficiência das avaliações do PROEB por diretores escolares em Minas Gerais. Tese (Educação). Universidade Federal de Minas Gerais. Belo Horizonte, 242 f, 2010. 


\section{DEVIR EDUCAÇÃO}

ISSN: 2526-849X

SOUSA, Sandra Zákia. Avaliação externa e em larga escala no âmbito do estado brasileiro: interface de experiências estaduais e municipais de avaliação da educação básica com iniciativas do governo federal. In: BAUER, Adriana; GATTI, Bernardete A. (Orgs.). Vinte e cinco anos de avaliação de sistemas educacionais no Brasil: implicações nas redes de ensino, no currículo e na formação de professores. Florianópolis: Insular, 2013. p 61-100.

SOARES, José Francisco; XAVIER, Flávia Pereira. Pressupostos educacionais e estatísticos do Ideb. Educação \& Sociedade, v. 34, n. 124, p. 903-923, 2013.

VIANNA, Heraldo Marelim. Avaliação e o avaliador educacional: depoimento. Estudos em Avaliação Educacional. São Paulo: FCC, 1999.

VIDAL, Eloisa Maia; VIEIRA, Sofia Lerche. Gestão educacional e resultados no Ideb: um estudo de caso em dez municípios cearenses. Estudos em Avaliação Educacional, São Paulo, v. 22, n. 50, p. 419-434, set./dez. 2011.

WERLE, Flávia Obino Corrêa. Experiências do estado do rio grande do sul em destaque: interfaces com as políticas de avaliação federais. In: Vinte e cinco anos de avaliação de sistemas educacionais no Brasil: implicações nas redes de ensino, no currículo e na formação de professores. BAUER, Adriana; GATTI, Bernardete A. (Orgs.). Florianópolis: Insular, 2013. p 193-210. 